\title{
Effectiveness of Learner-Centered Teaching in Modifying Attitude Towards EFL and Developing Academic Self-Motivation Among the 12th Grade Students
}

\author{
Sumaya A. Ahmed ${ }^{1} \&$ Maysoon A. Dakhiel ${ }^{2}$ \\ ${ }^{1}$ College of Education, Jeddah University, Saudi Arabia \\ ${ }^{2}$ Curriculum and Instruction of English Language, Faculty of Education, Jeddah University, Saudi Arabia \\ Correspondence: Maysoon A. Dakhiel, College of Education, Jeddah University, Saudi Arabia.
}

Received: January 25, 2019 Accepted: March 14, 2019 Online Published: March 17, 2019

doi: 10.5539/elt.v12n4p139 URL: https://doi.org/10.5539/elt.v12n4p139

\begin{abstract}
The present study aimed to identify the effectiveness of learner-centered teaching in modifying attitude towards EFL and developing academic self-motivation. The sample consisted of (35) $12^{\text {th }}$ grade students (in one of the high schools of Jeddah, Saudi Arabia, for the academic year 2017/2018). To achieve the study objectives, a training program based on three-strategies learning modules (Cooperative Learning: Think, Pair, Share, and Think out Loud) was prepared. The pre and posttest for the scales of attitude towards EFL and academic self-motivation were applied, along with active learning-based training sessions (Cooperative Learning: Think, Pair, Share, and Think out Loud). The application lasted (8) weeks, where the quasi-experimental method was utilized. The results showed statistically significant differences between the average scores of the respondents in the pre and posttest for the scales of attitude towards EFL and academic self-motivation in favor of the posttest. Finally, some recommendations were made in the light of the study results.
\end{abstract}

Keywords: learner-centered teaching, attitude towards EFL, academic self-motivation

\section{Introduction}

Since the beginning of the last century, English language has spread out throughout the world. Currently, it is the most influential language, so it is necessary to learn English. In Kingdom of Saudi Arabia, learning English starts from the early primary stage. However, traditional teaching methods did not achieve satisfying cognitive or non-cognitive outcomes among learners. This is because they focus on memorization and automatically training on typical language patterns. Some papers such as (Sa'ada et al., 2006) criticized the traditional method for it lacked changing students' attitudes. Besides, it neither developed higher-order thinking skills among students, nor it maintained the learning retention effect.

Chomsky is credited for the quantum leap in understanding language learning since he was the first one to criticize the traditional method which is based on behavioral attitude. He also called for the cognitive attitude in language learning (Strickland, 2001). This is because language is seen as a psychological phenomenon of cognitive nature (Widdowson, 2003).

Consequently, educators have turned to utilize methods of cognitive learning which are the baseline of designing teaching practices because of their learner-centered factors. In addition, the cognitive methods maintain that the process of learning takes place according to internal cognitive processes expressed by the learner's ability to understand information as well as to absorb, retrieve and utilize it in similar situations instead of memorizing it (Darwza, 2004). According to cognitive learning, learners are active in search for knowledge in order to develop it (AlZayyat, 2004). Learner-centered teaching reflects cognitive theories that assure that learning involves learners' active efforts in forming or building projects that help them to understand information. Actually, learners establish knowledge according to the information resulted by their active effort (Sa'eed \& Eid, 2006).

Learner-centered teaching is based on the following two hypotheses: First, learning is basically an active process performed by the learner, and secondly, according to many studies, learning reaches its peak when learners are involved into a learning situation. It can take place in any educational stage ranging from pre-school to higher studies, within small or large numbers depending on the readiness of learners and on the diversity of the 
educational environment (Mckinney, 1998). Strategies of learner-centered teaching help achieve affective objectives including forming and developing positive attitude towards the subject (Abdel Wahhab, 2005) and to provide the internal desire to learn (motivation) (Stahle, 1992; Johnson \& Johnson, 1992). Active learners get their own motivation internally, i.e., internal interests, questions and needs lead learners to discover, try and build new experience (Jubran, 2002). Utilizing those strategies requires learners to ask questions, move, interact with all the elements of the educational situation, as well as to practice speaking, listening, reading and writing (Wike, 2017).

Learner-centered teaching involves cooperation between students by dividing them into small groups during educational activities, which gives them a chance to discuss their expectations, interpretations, procedures and the data they get with the help of their peers before finishing the activity. Learning within cooperative groups deeply affects the whole personality of learners: cognitively, emotionally and socially $(\mathrm{H}$. H. Zaytoun \& K. A. Zaytoun, 2003). Conwell and Catherine (1998) concluded that cooperative learning had led to developing students' perceptions and increasing their level of self-esteem, academic achievement and feelings. Moreover, the study of (McCurdy, 1996) showed the positive effect of cooperative learning on developing academic self-motivation among learners in addition to increasing their participation in classroom activities and educational assignments.

In fact, attitude is one aspect of social motives acquired during socialization (AlTaweel, 2001). It affects one's qualitative motives and directs their behavior being an acquired general tendency that is relatively approved but emotionally acquired. Additionally, academic motivation is related to different teaching strategies and methods that are utilized in the educational process such as active learning (Komarraju \& Karau, 2008). Some studies showed that there was statistically positive significant relation between internal motivation and all of the following: employing effective learning strategies, positive attitudes towards the school and selecting difficult tasks.

Reviewing the literature related to the present study in Arabic and English databases showed that the field of EFL lacked studies handling all the variables of the present study together. Pieces of literature review were limited to only one strategy, i.e. cooperative learning strategy in EFL classrooms. For example, AlSebahy (2006) yielded that there were statistically significant differences between the average scores of the control group and the experimental group in favor of the experimental group as for the attitude towards English language. The experimental group taught by the strategy of mastering cooperative learning. Corder's thesis (1999) proved the effectiveness of the strategy of cooperative learning in developing motivation among the respondents. Another study concluded that cooperative learning has had a medium effect on increasing student's motivation for learning and achievement (Chen et al., 2005).

Applying learner-centered teaching requires diversity in employing teaching strategies because utilizing only one strategy in all different educational situations is ineffective in achieving the educational objectives. Consequently, the present study depends on utilizing three strategies in teaching EFL.

\section{Statement of the Problem}

Learner-centered strategies are vital for forming positive attitudes towards subjects and increasing internal motivation for learning. However, teaching styles utilized in teaching EFL at high-schools are still limited. This is proved when many Saudi universities re-introduce EFL in the Preparatory Year as an academic prerequisite. In addition, many EFL teachers depend on traditional methods such as lectures and theoretical presentations which negatively affect forming positive beliefs and attitudes towards EFL and also affect students' academic self-motivation. Therefore, teachers have to employ teaching strategies that meet the objectives of modern education in order to make learners more active and effective in seeking knowledge instead of receiving it from teachers. In fact, students learn and think better when they practice skills. Moreover, one major objective of learning is that students learn how to learn and how to be active and effective in the learning situation; hence they become the core of any educational process.

Accordingly, the problem of the present study lies in the following major question:

What is the effectiveness of learner-centered teaching in modifying attitude towards EFL among the $12^{\text {th }}$ grade students?

This major question can be subdivided into two minor ones:

1) What is the effectiveness of learner-centered teaching (Cooperative Learning, Think, Pair, Share, and Think out Loud) in modifying attitude towards EFL among the $12^{\text {th }}$ grade students?) 
2) What is the effectiveness of learner-centered teaching (Cooperative Learning, Think, Pair, Share, and Think out Loud) in modifying academic self-motivation among the $12^{\text {th }}$ grade students?)

\subsection{Objectives}

The present study aims to identify:

1) The effectiveness of learner-centered teaching (Cooperative Learning, Think, Pair, Share, and Think out Loud) in modifying attitude towards EFL among the respondents.

2) The effectiveness of learner-centered teaching (Cooperative Learning, Think, Pair, Share, and Think out Loud) in modifying academic self-motivation among the respondents.

\subsection{Significance of the Study}

The significance of the present study lies in the following points:

- Learner-centered teaching is a fundamental method for it meets the individual needs of students and it enables them to take important decisions as for designing and planning the educational tasks and assignments. Thus, it provides them with a good opportunity to discuss their interests and problems with teachers. In addition, it helps them modify their own attitudes and motives.

- As far as the authors access databases, the present study is the first to treat modifying attitude towards EFL and developing academic self-motivation by utilizing learner-centered teaching in Saudi Arabia.

- The study results can help in attracting teachers' attention to utilizing learner-centered teaching in EFL classrooms in order to enhance learning.

\section{Study Concepts}

\subsection{Learner-centered Teaching}

It is procedurally defined as a group of procedures and practices that are planned according to the following strategies: (Cooperative Learning, Think, Pair, Share, and Think out Loud) based on some learning modules utilized in teaching EFL for the $12^{\text {th }}$ grade. Those modules require them to think, speak, discuss, cooperate, write, and finish some tasks.

A. Cooperative Learning Strategy:

It is procedurally defined as a group of procedures that learners follow when learning in small groups through effective group interaction in order to finish educational tasks related to the learning outcomes.

B. Think, pair, Share Strategy:

It is procedurally defined as a group of procedures that increase students' participation. It is an effective strategy for slowing down the lesson pace, broadening students' minds and giving them more time to think.

C. Think out Loud Strategy:

It is procedurally defined as a group of procedures that depend on dialogues between teacher and students or among students, where students express their minds about the learning topics. Here, questions and answers play a significant role in achieving the objectives.

\subsection{Attitude}

It is procedurally defined as an opinion that students adopt towards EFL, and it is explicit in how far they accept or reject learning and in their evaluation of the significance of the subject (English) in everyday life and in work environment. The present study measures attitude towards EFL by the total score a student gets in the 3-dimension scale prepared for that purpose.

\subsection{Academic Self-motivation}

It is procedurally defined as the extent of joy a student feels while performing tasks and the pursuit of doing those tasks regardless of how difficult they are with a continuous desire to do their best with a positive interaction with the new tasks in a joyful atmosphere leading to a desire and capacity to do extra voluntary tasks. The concept also refers to positive attitude towards learning. The present study measures academic self-motivation by the score a student gets in the scale prepared for that purpose.

\section{Limitations}

The present study is limited to: 
- $\quad$ The strategies of learner-centered teaching (Cooperative Learning, Think, Pair, Share, and Think out Loud) as an independent variable, and attitude towards EFL and academic self-motivation as two dependent variables.

- $\quad$ A sample of the $12^{\text {th }}$ grade students from a high school in Jeddah.

- $\quad$ The academic year 2017/ 2018.

\section{Hypotheses}

1)- There are statistically significant differences between the average scores of the respondents in the pre and posttest for the scale of attitude towards EFL in favor of the posttest.

2)- There are statistically significant differences between the average scores of the respondents in the pre and posttest for the scale of academic self-motivation in favor of the posttest.

\section{Procedures}

\subsection{Methodology}

The present study adopts the quasi-experimental method, Pre-Posttest Nonequivalent Control Group Design.

\subsection{Sample}

The sample was selected from the $12^{\text {th }}$ grade students at a school in Jeddah for the academic year $2017 / 2018$. The number of respondents was (35) students ranging from (18) to (19) years old with a mean of (18.30) and a standard deviation of (1.60).

\subsection{Tools}

a) The scale of attitude towards EFL

The authors prepared the scale of attitude towards EFL that covered (27) items in its first draft. The items were formulated positively and negatively and they were distributed to three dimensions: the content of the English course, which contained 9 items (No. 1, 4, 7, 10, 13, 16, 19, 22, 25), the value and significance of the English course, which contained 9 items (No. 2, 5, 8, 11, 14, 17, 20, 23, 26), and enjoying learning the English course which, contained 9 items (No. 3, 6, 9, 12, 15, 18, 24, 21, 27). Respondents replied to each item according to a five-point scale (strongly agree, agree, neutral, disagree, and strongly disagree). For grading positive items, (5) for "strongly agree", (4) for "agree", (3) for "neutral", (2) for "disagree", and (1) for "strongly disagree". In case of negative items (No. 1, 2, 3, 5, 15, 26), the Likert scale points were reversed.

The Scale's Psychometric Characteristics:

Validity: The Scale's Validity was verified by:

- The validity of the reviewers: The scale's first draft was reviewed by (9) reviewers specialized in Psychology and Teaching Methodology in the Faculty of Education (Jeddah University) in order to evaluate the appropriateness of the items to each dimension, wordiness, and how far they matched the age they targeted. The ratio of their agreement on each item ranged from $85 \%$ to $90 \%$.

- Internal consistency: The validity of internal consistency was verified by measuring the correlation coefficients between the items and the total score of the minor scale to which the items belonged. All the values of the correlation coefficients were significant at the level of (0.01). As for the dimension of the content of the English course, the values were rated between (0.72) and (0.80.) The values of the dimension of enjoying learning the English course were rated between (0.70) and (0.79), while the values of the dimension of the value and significance of the course were rated between $(0.67)$ and $(0.69)$. Those values refer that the internal consistency of the scale items is high and it can measure the attitude towards the English course.

- The correlation coefficients of the sub scales were calculated together. The values of the correlation coefficients were significant at the level of (0.01). They ranged between $(0.68)$ and $(0.85)$.

- Construct Validity: The scale was applied to (300) students, where the Principal Component Analysis (PCA) was utilized, factors were horizontally Varimax-rotated, and Kaiser Criterion was at least (0.4) for saturated items. The factor analysis resulted in three factors saturated in the scale items, which verified the validity of the theoretical construct of the scale. The first factor was saturated in (9) items measuring the attitude towards the content of the English course, ranged from (0.50) to (0.77). It showed variance rated (35.21\%). The second factor was saturated in (9) items measuring the attitude towards the value and significance of the English course, ranged from (0.43) to (0.76). It showed variance rated $(32.26 \%)$. The third factor was saturated in (9) items related to measuring the attitude towards enjoying learning the English course, ranging from 0.41 to 0.51 , and it showed variance rated (13.17\%). 
Reliability: The Scale's Reliability was verified by:

- Re- test: The scale's reliability was measured by re- testing (60) high-school students; three weeks interval for the retest. Then Cronbach's alpha $(\alpha)$ was calculated. Results were shown as follows:

Table 1. Coefficient values for the reliability of attitude towards EFL

\begin{tabular}{lll}
\hline Dimensions of the attitude scale & The value of Cronbach's Alpha $(\alpha)$ & Re- test \\
\hline The content of the English course & 0.66 & $0.83^{* *}$ \\
The value and significance of the English course & 0.63 & $0.80^{* *}$ \\
Enjoying learning English & 0.69 & $0.89^{* *}$ \\
The total score of the scale & 0.82 & $0.92^{* *}$ \\
\hline
\end{tabular}

Note. $* *$ Statistically significant at the level of $(0.01)$

Table 1 showed that all the values of reliability were high and significant, so the scale is highly reliable.

b) The scale of academic self-motivation, prepared by Ahmad (2012)

The authors accessed to some scales of academic motivation and achievement and some theoretical frameworks of academic self-motivation. Then they utilized the scale of academic self-motivation prepared by Ahmad (2012). It contained (25) items for measuring academic self-motivation.

The Scale's Psychometric Characteristics:

Validity: The Scale's Validity was verified by:

- The validity of the reviewers: The scale's first draft was reviewed by 9 reviewers specialized in Psychology in the Faculty of Education (Taif University) in order to evaluate the appropriateness of the items to each dimension, wordiness, and how far they matched the age they targeted. The ratio of their agreement on the items ranged from $(88 \%)$ to $(100 \%)$.

- Internal Consistency: The validity of internal consistency was verified by calculating the correlation coefficients between the score of each item and the total score of the scale. All the values of the correlation coefficients were significant at the level of (0.01), ranged from (0.65) to (0.76), which verified the high internal consistency of the scale in measuring academic self-motivation.

Reliability: The Scale's Reliability was verified by:

Re-test: The scale's reliability was measured by re- testing (60) high-school students; three weeks interval for the retest. Then Cronbach's alpha $(\alpha)$ was calculated. Results were shown in Table 2.

Table 2. Coefficient values for the reliability of academic self-motivation

\begin{tabular}{lll}
\hline Scale & The value of Cronbach's Alpha $(\alpha)$ & Re-retest \\
\hline Academic self-motivation & 0.89 & $0.90^{* *}$ \\
\hline
\end{tabular}

Note. ${ }^{* *}$ Statistically significant at the level of $(0.01)$.

Table 2 showed that all the values of reliability were high and significant, so the scale is highly reliable.

3- Preparing the sessions of the training program

- The training sessions were prepared to include the following sections: objectives, tools, content, procedures and evaluation.

- The content was prepared to relate to the objectives, which were considered as the criteria for selecting, preparing and organizing the content, activities and teaching aids. The content was prepared from references and textbooks specialized in EFL. It included a group of activities appendicized to the content of each sub-strategy in order to foster students' understanding of the material of each strategy. The following points were taken into consideration when preparing the learning and teaching activities:

- $\quad$ They should be related to the objectives, content, teaching methods and available resources. 
- They should allow learners' effective and positive participation.

- They should be varied and include both theoretical and practical tasks.

- Early and positive feedback should be given to learners so that they would think positively about their effort.

- Tasks should be assigned not to be too easy or too difficult in order to ensure success opportunities for students.

- Teachers should guide students to think of the significance of what they are learning.

- Teachers should help students feel valued in classrooms.

- $\quad$ Each strategy should be followed by quiz in order to identify how far students got it.

- $\quad$ Training sessions were organized according to the following principles:

- The strategy subdivided into some minor procedures.

- $\quad$ Studying the utilized strategies by presenting some theoretical content and guidelines on how to implement

it.

- Applying the strategy practically by training students on how to utilize it through guiding and independent activities.

- The program was comprised of (16) training sessions; students were trained during the class time, i.e. 45 minutes for each session.

- Training sessions were evaluated by (9) reviewers specialized in educational psychology and EFL methodology. Their comments and notes were satisfied and taken into consideration while preparing the final draft of the training program.

- The EFL content was introduced to the respondents.

- Posttest Conducted: After finishing the training, the scales of attitude towards EFL and academic self-motivation were applied to (35) students.

\section{Results and Discussion}

\subsection{Results of the First Hypothesis}

The first hypothesis was: "There are statistically significant differences between the average scores of the respondents in the pre and posttest for the scale of attitude towards EFL in favor of the posttest".

The first hypothesis was verified by calculating arithmetic means, standard deviations, and Paired-Samples $\mathrm{T}$-Test in order to get the differences in the average scores of the respondents in the pre and posttest for the total score in the scale of attitude towards EFL. Table 3 showed results of the statistical analysis.

Table 3. Differences between the average scores of the pre and posttest for the scale of attitude towards EFL

\begin{tabular}{|c|c|c|c|c|c|c|c|}
\hline \multirow{3}{*}{ Variable } & \multicolumn{2}{|c|}{ Arithmetic Means } & \multicolumn{2}{|c|}{ Standard Deviations } & \multirow{3}{*}{$\begin{array}{l}\text { Freedom } \\
\text { Degree } \\
\text { (FD) }\end{array}$} & \multirow{3}{*}{ T-Value } & \multirow[b]{3}{*}{$\eta 2$} \\
\hline & \multicolumn{2}{|l|}{ Pre test } & \multicolumn{2}{|l|}{ Post test } & & & \\
\hline & $\begin{array}{l}\text { Arithmetic } \\
\text { Mean }\end{array}$ & $\begin{array}{l}\text { Standard } \\
\text { Deviation }\end{array}$ & $\begin{array}{l}\text { Arithmetic } \\
\text { Mean }\end{array}$ & $\begin{array}{l}\text { Standard } \\
\text { Deviation }\end{array}$ & & & \\
\hline $\begin{array}{l}\text { The total score of the } \\
\text { scale of attitude } \\
\text { towards EFL }\end{array}$ & 88.74 & 13.54 & 108.00 & 10.68 & 34 & $6.53 * *$ & 0.90 \\
\hline
\end{tabular}

Note. ${ }^{* *}$ Statistically significant at the level of $(0.01)$.

Table 3 showed that there were statistically significant differences at the level of $(0.01)$ for the scale of attitude towards EFL in favor of the posttest. Those results showed the effectiveness of learner-centered teaching strategies (Cooperative Learning, Think, Pair, Share, and Think out Loud) in modifying attitude towards EFL.

That result partially agreed with (AlSebahy, 2006), which stated the effectiveness of cooperative learning in students' attitudes towards EFL. It also agreed with (Abdel Wahhab, 2005), which referred that active learning strategies develop positive attitude towards subjects. 
Results of the first hypothesis were consistent with the literature reviewed about the possibility of modifying students' attitudes by allowing them to participate actively and effectively in the educational situation. They agree with Jean Piaget's view that learning is an active process where learners first interact with the environment around them, and then they formulate knowledge by themselves. When learners are allowed to compare and discuss results together, they achieve real learning. On the other hand, when they memorize and recite information, they are not successfully learned. Therefore, Piaget's major principle is to consider education as an active process done by learners, not for them (AlKhaleely, Haider, \& Younes 1996).

This result can be attributed to the positive effects of learner-centered teaching. Actually, the respondents felt responsible for their own learning and for their self-management. Besides, they managed to master the content. All of that resulted in developing positive attitudes towards learning and it also encouraged them to explore their attitudes. This proves that tasks performed by learners are more valuable for them.

In order to calculate the effect size of the independent variable (learner-centered teaching strategies) on the dependent variable (attitude towards EFL), Eta-Squared $\eta 2$ was applied. Table 3indicated that the value of ( $\eta 2$ ) is $(0.90)$, which meant that the variance resulted by the experimental processing (utilizing learner-centered teaching strategies) in the regular variance of the dependent variable is $(90 \%)$. Thus, this percentage indicated a high effect size of the independent variable (the experimental processing) because Abu Hattab and Sadiq (1996) stated that effect was high when rated (15\%) and more of the total variance (p. 442). The percentage also indicated that the utilized strategies are highly effective in modifying the respondents' attitude towards EFL.

\section{Results of the Second Hypothesis}

The second hypothesis was: "There are statistically significant differences between the average scores of the respondents in the pre and posttest for the scale of academic self-motivation in favor of the posttest".

That hypothesis was verified by calculating arithmetic means, standard deviations, and Paired-Samples T-Test in order to get the differences in the average scores of respondents in the pre and posttest for the total score in the scale of academic self-motivation. Table (4) showed results of the statistical analysis.

Table 4. Differences between the pre and posttests for academic self-motivation

\begin{tabular}{|c|c|c|c|c|c|c|c|}
\hline \multirow{3}{*}{ Variable } & \multicolumn{2}{|c|}{ Arithmetic Means } & \multicolumn{2}{|c|}{ Standard Deviations } & \multirow{3}{*}{$\begin{array}{l}\text { Freedom } \\
\text { Degree (FD) }\end{array}$} & \multirow{3}{*}{ T-Value } & \multirow{3}{*}{$\eta 2$} \\
\hline & Pre test & & Post test & & & & \\
\hline & $\begin{array}{l}\text { Arithmetic } \\
\text { Mean }\end{array}$ & $\begin{array}{l}\text { Standard } \\
\text { Deviation }\end{array}$ & $\begin{array}{l}\text { Arithmetic } \\
\text { Mean }\end{array}$ & $\begin{array}{l}\text { Standard } \\
\text { Deviation }\end{array}$ & & & \\
\hline $\begin{array}{l}\text { Total score of academic } \\
\text { self-motivation }\end{array}$ & 31.93 & 10.47 & 59.06 & 12.23 & 34 & $4.09 * *$ & 0.32 \\
\hline
\end{tabular}

Note. ${ }^{* *}$ Statistically significant at the level of $(0.01)$.

Table 4 showed that there were statistically significant differences at the level of $(0.01)$ in favor of the posttest of academic self-motivation. That result showed the effectiveness of utilizing the strategies of learner-centered teaching (Cooperative Learning, Think, Pair, Share, and Think out Loud) in developing academic self-motivation. In their Master thesis, Carroll and Leander (2001) asserted that those strategies helped employ multiple activities, which led to reducing negative activities such as negative listening and taking notes during lectures. Thus, those strategies motivated students for learning.

That result partially agrees with (Corder, 1999 \& Chen et al., 2005), which showed the positive effect of cooperative learning strategy on increasing motivation for learning English. It also agreed with pieces of literature review confirming that a teaching method based on active interaction between students increases their achievement and motivation for positive learning as well as it allowed for individual differences among students (Abuel Nasr \& Jamal, 2005).

Moreover, it agreed with (Dornye, 1997), which stated that active learning had a deep effect on academic self-motivation on many levels through a group of motives related to active learning (cooperative learning): motives related to the group, motives related to the educational task and motives related to learners. Additionally, it agreed with (Komarraju \& Karau, 2008) which asserted that academic motivation was related to different teaching strategies and methods utilized in the educational process such as active learning and other 
learner-centered teaching strategies.

That result is supported by the self-determination theory. Ryan and Deci believed that any human being needs to feel competent and autonomous. Deci explained that internally-motivated activities satisfy one's needs for competency and self-autonomy, while externally-motivated activities weakened them. He added that students of self-determined motivation are more likely to pursue learning, and to adapt and understand well. Competency paves the way to motivation. Motivation is urged when learners overcome expected challenges and get valuable and significant feedback on their performance (Sternberg \& Williams, 2002). The present study adopted that perspective while preparing the training program.

In order to calculate the effect size of the independent variable (learner-centered teaching strategies) on the dependent variable (academic self-motivation), Eta-Squared $\eta 2$ was applied. Table 4 indicated that the value of $(\eta 2)$ was $(0.32)$ which meant that the variance resulted by the experimental processing (utilizing learner-centered teaching strategies) in the regular variance of the dependent variable was (32\%). Thus, this percentage indicated high effect size for the independent variable (the experimental processing). The percentage also showed that the utilized strategies were highly effective in developing the respondents' academic self-motivation.

\section{A Comment on the Results}

Finally, those results were reached by designing and applying a training program to students. The training program led to modifying their attitude towards EFL and developing their academic self-motivation. This assures that students actively and effectively express themselves. Informal situations with autonomy and freedom of thought also helped reach that result. Therefore, designing learning environments should not be based on making students record information negatively (teacher-centered learning). Rather, it should seek to engage students in learning (learner-centered teaching).

The results indicated that the utilized strategies focused on learners as the core of education. Thus, those strategies avoid making learners negative by creating learning environments that help them take part in learning rather than just listening. That allowed for knowledge building, which enhanced learners' ability to recall information. Active learning also required learners to employ higher-order thinking skills such as analysis, evaluation and creation. It also required their participation in varied activities such as reading, writing, listening and discussion. Actually, it paid great attention to help learners in exploring their own attitudes and values (Fox Cordamone \& Rue, 2003).

The study results also confirmed that group learning developed learners' belonging and loyalty for the group, increased their common enjoyment; appropriate for the supervisory role of teachers to introduce instructions and presentations. The study concluded that learners learn from their peers more than their teachers due to the increasing of student speaking time. The communication approach asserts that learners should get more involved with their peers for using language and should interact more freely and autonomously. It enabled teachers to monitor groups while learners are doing tasks. It motivated group learning and put the responsibility of learning on all the members, who exchanged experience, so it was fast and easy to be organized as stated by (Harmer, 2004).

\section{Recommendations}

Some recommendations have been made, including:

- The need for educators in different educational institutions to utilize learner-centered teaching strategies.

- Holding training programs for teachers and faculty members on utilizing learner-centered teaching strategies which would develop learners' positive attitudes towards courses and motivate them for learning.

\section{References}

Abdel Wahhab, F. M. (2005). Effectiveness of some active learning strategies in achieving and developing some life-long learning skills and scientific tendencies among fifth-grade students. Egyptian Association for Science Education, Journal of Science Education, 8(2), 127-170.

Abu Hattab, F., \& Sadiq, A. (1996). Methods and Approaches of Statistical Analysis of Psychological, Educational and Social Sciences. Cairo: The Anglo Egyptian Bookshop.

Abu Nasr, H., \& Jaml M. (2005). Cooperative Learning: Philosophy and Practice. Al- Ain: University Books Publication House.

Ahmad, S. A. (2012). Effectiveness of active learning strategies in teaching psychological and educational statistics in modifying attitude towards statistics and developing academic self-motivation. Arab Journal of 
Education, Arab League Educational, Cultural and Scientific Organization (ALECSO), 32(1), 98-143.

AlDeeb, M. M. (2006). Studies in Cooperative Learning Styles. Cairo: The World of Books.

AlKhaleely, K. Y., Haider, A., \& Younes, M. J. (1996). Teaching Science for General Education. Dubai: Dar Al Qalam Publishing \& Distribution.

AlSebahy, A. A. (2006). Impact of Mastery Cooperative Learning on EFL among Third-grade Middle Students and their Attitudes towards EFL in Al-Ahsa. (Unpublished PhD Dissertation, Faculty of Education for Girls, King Abdulaziz University).

AlTaweel, E. A. (2001). Features of Contemporary Psychology (4th ed.). Alexandria: Dar AlWafaa.

AlZayyat, F. M. (2004). Educational Psychology from the Associated Perspective and Cognitive Perspective. Cairo: Dar Annashr for Universities.

Carroll, L., \& Leander, S. (2001). Improve Motivation through the Use of Active Learning Strategies. Unpublished Master Dissertation, Saint Xavier University.

Chen, M. L. (2005). The effects of the cooperative learning approach on Taiwanese English student's motivation, English listening, reading, and speaking competencies (China). ERIC, No, AA13168533.

Conwell, A., \& Catherine, L. (1998). Student perceptions when working in cooperative problem-solving groups. A Paper presented at the North Carolina science teacher association convention. Eric document No: ED 313455.

Corder, G. W. (1999). Motivating Middle Grader Using a Cooperative Learning Approach. M. A. action research project, US, Illinois: Saint Xavier University.

Darwza, A. (2004). Basics of Educational Psychology. Amman: Al-Shorouk Publication House.

Dornyei, Z. (1997). Psychological processes in cooperative language learning: Group dynamic and motivation, The Modern Language Journal, 81, 482-93. https://doi.org/10.1111/j.1540-4781.1997.tb05515.x

Fox-Cordamone, L. \& Rue, S. (2003). Students responses to active learning strategies: An examination to small -group and whole - class discussion. Research for Education Reform, 8(3), 3-15.

Harmer, J. (2004). The practice of English Language Teaching (3rd ed.). New York: Longman. https://doi.org/10. $1093 / \mathrm{elt} / 58.1 .80$

Johnson, D. \& Johnson, R. (1992). Approaches to implementing cooperative learning in the social studies classroom. In R. Stahl, \& R. Van Sickle, (Eds.), Cooperative Learning in the Social Studies Classroom: An Introduction to Social Study (pp. 8-15). Washington, D.C.: National Council for the Social Studies.

Jubran, W. (2002). Active Learning as Real Learning. Palestine, Ramallah: Publication of the Centre of Media and Marketing.

Komarragu \& Karau (2008). Relationships between the perceived value of instructional techniques and academic motivation. Journal of Instructional Psychology.

McCurdy, A. (1996). A study of cooperative learning strategies on the motivation of high-ability student, An Action Research project presented for Elementary Education licensure, University of Tennessee, 1-19.

McKinney, K. (1998). Engaging students through active learning. News Letter from the Center for the Advancement of Teaching. Illinois State University.

Sa'ada, J. A., Okeil F., Zamel M., Eshtia J., \& Abu Arkoob, H. (2006). Active Learning: Theory and Practice. Jordan: Al-Shorouk Publication House.

Sa'eed, A. M. \& Eid, R. A. (2006). Effectiveness of some active learning strategies in teaching social studies in achieving and developing some problem solving skills and among middle-stage students. Journal of Studies in Curricula and Teaching Methods, (111), Cairo: Egyptian Association of Curricula and Teaching Methods.

Stahl, R. (1992). From "Academic strangers" to successful members of a cooperative learning group: An inside-the-learner perspective. In R. Stahl, \& R. Van Sickle (Eds.), Cooperative Learning in the Social Studies Classroom: An Introduction to Social Study (pp. 8-15). Washington, D.C.: National Council for the Social Studies.

Strickland, B. (2001). The Gale Encyclopedia of Psychology (2nd ed.). USA: Gale Group.

Sternberg, R. J., \& Williams, W. M. (2002). Educational Psychology. Boston: Allyn \& Bacon. 
Widdowson, H. G. (2003). Linguistics (7th ed.). Oxford: Oxford University Press.

Wike, R. (2017). The effect of active learning on student characteristics in a Hunan physiology course for non-majors. Advance Physiology Education, 16(3), 207-223.

Zaytoun, H. H., \& Zaytoun, K. A. (2003). Learning and Teaching in Constructionism. Cairo: The World of Books.

\section{Copyrights}

Copyright for this article is retained by the author(s), with first publication rights granted to the journal.

This is an open-access article distributed under the terms and conditions of the Creative Commons Attribution license (http://creativecommons.org/licenses/by/4.0/). 